International Journal of Biology, Pharmacy and Allied Seiences (IJBPAS) 'A Bridge Betuen Caboratory and Qnendo' WwW.ijbpas.com

\title{
ROLE OF MUSIC THERAPY IN THE FIELD OF MEDICINE
}

\section{LAKSITA ${ }^{1}$ AND A. JOTHI PRIYA ${ }^{2 *}$}

1: Saveetha Dental College and Hospitals, Saveetha Institute of Medical and Technical Sciences (SIMATS), Saveetha University, Chennai - 77,

2: Assistant Professor, Department of Physiology, Saveetha Dental College and Hospitals, Saveetha Institute of Medical and Technical Sciences (SIMATS), Saveetha University, Chennai - 77

*Corresponding Author: E Mail: Dr. A. Jothi Priya: jothipriya.sde@saveetha.com Received 19 ${ }^{\text {th }}$ March 2021; Revised 20 ${ }^{\text {th }}$ April. 2021; Accepted $19^{\text {th }}$ May 2021; Available online $1^{\text {st }}$ Aug. 2021 https://doi.org/10.31032/IJBPAS/2021/10.8.1012

\begin{abstract}
Music therapy therapy needs a variety of methods of allied fields to contribute scientific findings, including mathematics, natural sciences, behavioral and social sciences, as well as the arts. Neuroscientific research in music is giving rise to new ideas, perspectives, and methods; they seem to be promising prospects for a possible contribution to a theoretical and empirical scientific foundation for music therapy. The aim of our study is to assess the knowledge about the role of music therapy and its effects in the field of medicine. For this purpose, 100 participants were made to fill the questionnaire through an online survey link and the responses were analysed through descriptive statistics using SPSS software. The results are strongly positive and offer support for the use of music therapy in treating patients. It is also known that participation in music therapy significantly decreases post meal related anxiety and distress in comparison to standard post meal support therapy. This study provides support for the future funding of inpatient music therapy programs and contributes to the evidence base for the use of music therapy with this population.
\end{abstract}

Keywords: Music therapy; Medicine; Stress; Anxiety; Health 


\section{INTRODUCTION}

Music is an art form, and cultural activity, whose medium is sound. Music is performed with a vast range of instruments and vocal techniques ranging from singing to rapping. In many cultures, music is an important part of people's way of life, as it plays a key role in religious rituals, rite of passage ceremonies (e.g., graduation and marriage), social activities (e.g., dancing) and cultural activities ranging from amateur karaoke singing to playing in an amateur funk band or singing in a community choir. Music also plays an important role in the medical field by treating patients medical problems.

Participation in music therapy can improve the quality of life, interpersonal relationships and social skills of people with mental illness [1-3]. Music therapy can help promote selfdetermination and collaboration with patients through focusing on strengths and resourceoriented practice [4]. The therapeutic effects of music are being recognised increasingly in the field of rehabilitation medicine. More music therapists are being employed in physical medicine and rehabilitation centres, with the goal of using music therapy services to assist in the physical recovery and health maintenance of clients [5]. The role of music in 90 medicine is primarily supportive and palliative. The supportive role of music has a natural field of application in palliative medicine and terminal care [6-11]. Music is well tolerated, inexpensive, with good compliance and few side effects [12]. The more recent ascendance of holistic medicine is creating a change in the attitude held by practitioners and the public to a position of greater acceptance of music therapy as a healing mode [13]. Use of music therapy to promote feelings of empowerment and equality are arguably expressly important in inpatient mental health settings that may otherwise provide little opportunity for selfdetermination $[\mathbf{1 4}, \mathbf{1 5}]$. Music therapy may offer motivation for recovery from eating disorders, distraction from negative thoughts and feelings, a sense of autonomy and creative expression. Music also plays an important role in sleep and sleep patterns [16].

Music therapy may offer motivation for recovery from eating disorders, distraction from negative thoughts and feelings, a sense of autonomy and creative expression. Case studies derived from patient experiences have described feelings of renewed self confidence and empowerment through participation in music therapy. In a study it is known that, Participants' anxiety decreased significantly pre-post the music therapy group compared 
with standard post meal support therapy [17]. According to Dr. Daniel Levitin, "Singing and instrumental activities might have helped our species to refine motor skills, paving the way for the development of the exquisitely fine muscle control required for vocal or signed speech." Evidence suggests that music therapy is beneficial for all individuals, both physically and mentally. Benefits of music therapy include improved heart rate, reduced anxiety, stimulation of the brain, and improved learning.

Music therapy and music therapy research currently represent heterogeneous but growing fields. In their clinical work, music therapists experience music as an effective tool in the treatment of various illnesses. Despite this clinical observation, it is necessary in modern societies and current healthcare systems to prove the effectiveness and efficacy of psychological as well as medical treatments. The aim of our study is to assess the knowledge about the role of music therapy and its effects in the field of medicine.

\section{MATERIALS \& METHODS}

A cross - sectional and a self structured questionnaire containing 15 questions was prepared and circulated to the general population through an online link. This was approved by the scientific review board. The sample size of the study is 100 . The participants were within the age group of 18 30 years. The questionnaire included the basic demographic datas, such as age, gender, etc. The sampling method used was 'random sampling'. The statistics used to analyse the results was ANOVA using SPSS software. The results obtained from the survey assessed the knowledge of the participants about music therapy. The results of each output variable are represented through pie charts.

\section{RESULTS \& DISCUSSION}

100 people participate in the survey from the age group of 18 - 30 years. Both males and females participated. From that, 35\% were males and $65 \%$ were females.

Figure 1 represents that $47 \%$ of the participants listen to music for less than 2 hours in a day. $38 \%$ of the people listen for about 2-3 hours and $15 \%$ of the people listen to music for more than 3 hours a day. Figure 2 represents that, for $90 \%$ of the people, music helps in stress reduction and for $10 \%$ of the people music rarely helps in stress reduction. Figure 3 represents that, for $90 \%$ of the people, music helps in changing their mood and for $10 \%$ of the participants, music does not help them to change their mood. Figure 4 represents that, for $82 \%$ of the people responded that, undergoing music 
therapy reduces patients pain and $18 \%$ of the participants disagree that undergoing music therapy does not reduce patients pain. Figure 5 represents that $43 \%$ of the people said that music therapy improves respiration, lowers blood pressure, improves cardiac output, reduces heart rate and relaxes muscle tension.

Figure 6 shows that $88 \%$ of the people think that music therapy has an effect in treating patients medical problems and $12 \%$ of the participants think that music therapy does not have an effect in treating patients medical problems. Figure 7 represents that $71 \%$ of the people think that music therapy is well established in India and $29 \%$ of the participants think that music therapy is not well established in India. Figure 8 shows that $51 \%$ of the participants responded that they listen to music when they have any problem. $49 \%$ of the participants responded that they sometimes or rarely listen to music when they have any medical problems. Figure 9 shows that, $84 \%$ participants said that Male listen to more music than female and $16 \%$ participants responded vice versa. Figure 10 shows that $75 \%$ participants responded that undergoing music therapy is safe and $25 \%$ participants responded that undergoing music therapy is not safe. Figure 11 shows that, $75 \%$ of the participants said that they would refer the patients to undergo music therapy and $25 \%$ of the participants would not refer the patients to undergo music therapy. Figure 12 shows that, $78 \%$ of the participants said that music therapy improves anxiety and $22 \%$ of the participants said that undergoing music therapy will not improve anxiety.

The results are strongly positive and they offer support for using music therapy for treating patients. Music therapy is also used in treating many severe cases and medical issues [18-21]. In few studies, it is noted that music therapy decreases anxiety [18-19]. Whereas in our study, it shows that music therapy increases the anxiety level among the patients. It is well known that music is one of an engaging activity for young people and it is a motivating factor formation, participating in therapy [20], which is similar to that of our study. It is likely that participants considered music therapy as a non threatening and familiar activity in confronting medical settings [14, 15]. Previous music therapy research has focused on participants' experiences of music therapy sessions during their recovery $[\mathbf{2 1}, \mathbf{2 2}]$. Music therapy also plays an important role in physical and mental health [23-24].

The current study has positive implications for the use of music therapy in reducing patients' medical problems. However, the 
findings may be limited due to a number of limitation of this study is that the sample size factors. The research design was quasi - is less. A large number of participants, experimental and did not randomize randomization to control and intervention participants to each condition. Participants conditions and recruitment from different were recruited from one site which may hospital sites would benefit future research in affect the generalizability of the results. The this area.

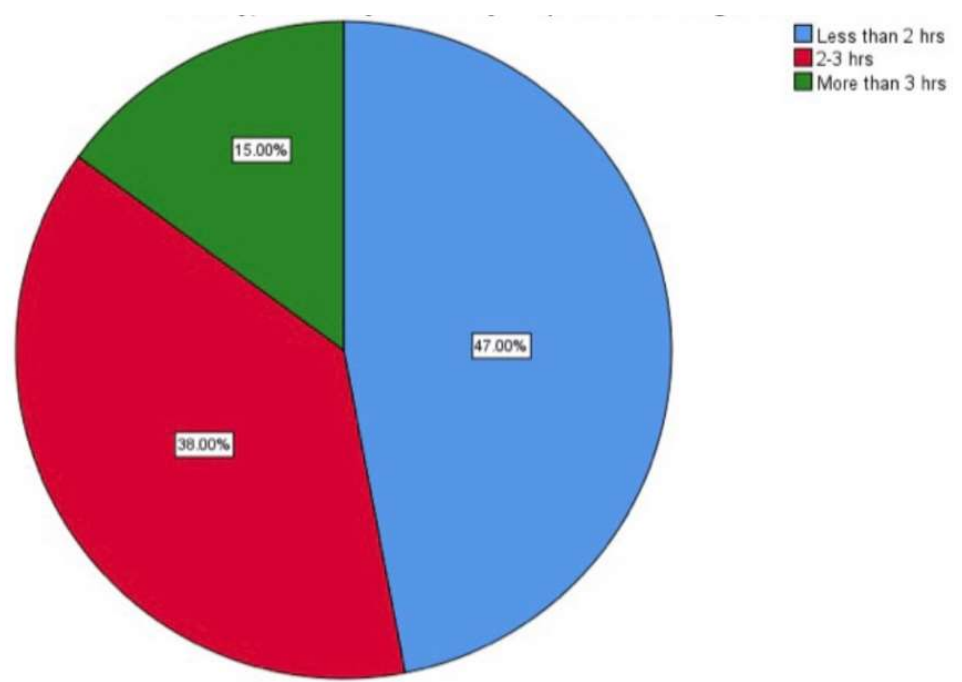

Figure 1: Pie chart representing the time spent by the participants in listening to music in a day. Majority $47 \%$ (blue) listens to music for less than two hours, $38 \%$ (red) listens for music between $2-3$ hours and minority $15 \%$ (green) listens to music for more than 3 hours

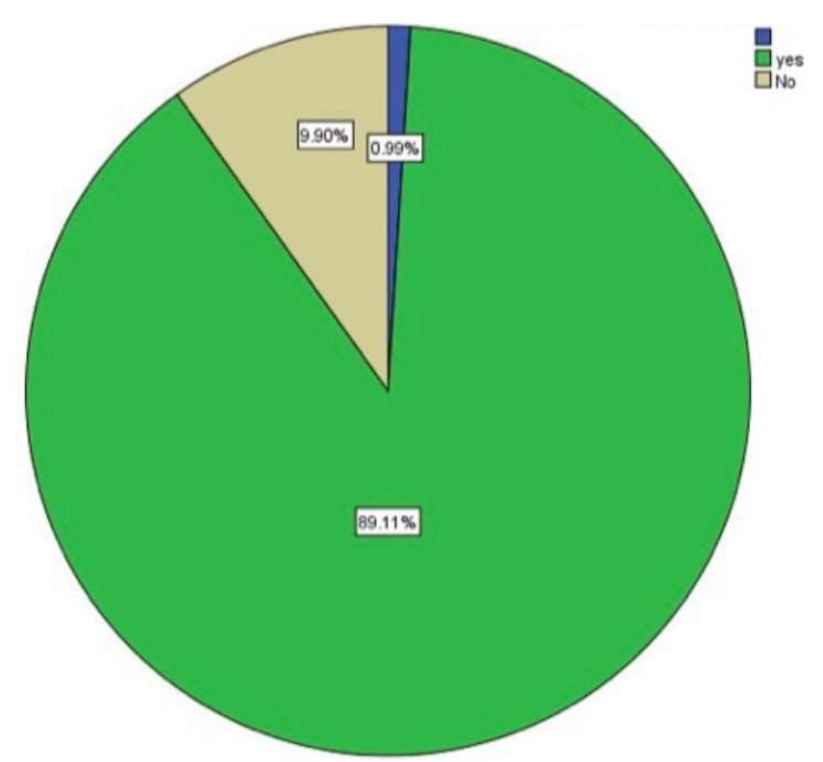

Figure 2: Pie chart representing participant's opinion on the role of music in stress reduction. Majority $90 \%$ (green) participant's agrees that listening to music helps in stress reduction and minority $10 \%$ (yellow) participant's disagrees that listening to music helps in stress reduction 


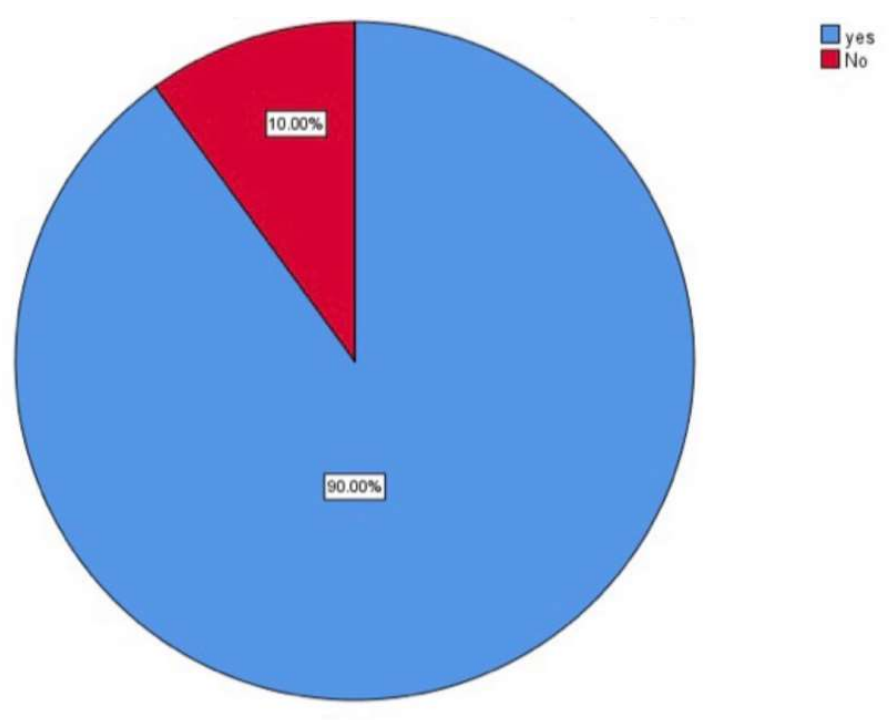

Figure 3: Pie chart representing participant's opinion in using music to change their mood. Majority $90 \%$ (blue) agrees that listening to music change their mood and minority $10 \%$ (red) disagrees that listening to music does not change their mood

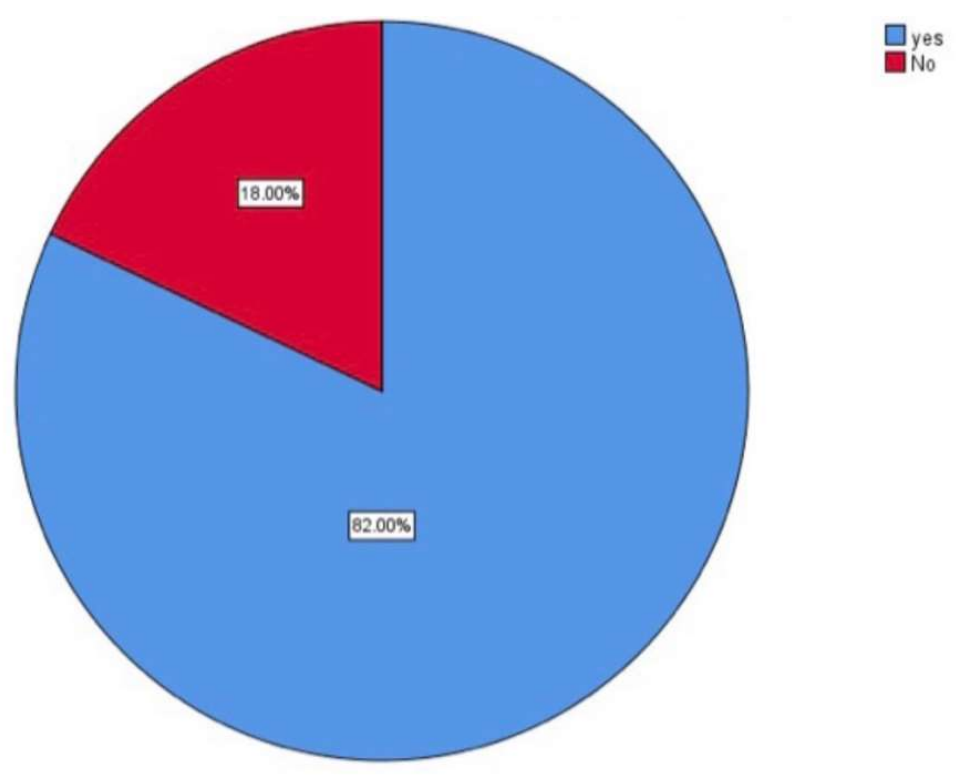

Figure 4: Pie chart representing participant's opinion on music therapy which reduces patients pain. Majority $82 \%$ (blue) agrees that music therapy reduces pain and minority $18 \%$ (red) disagrees that music therapy reduces patients pain 

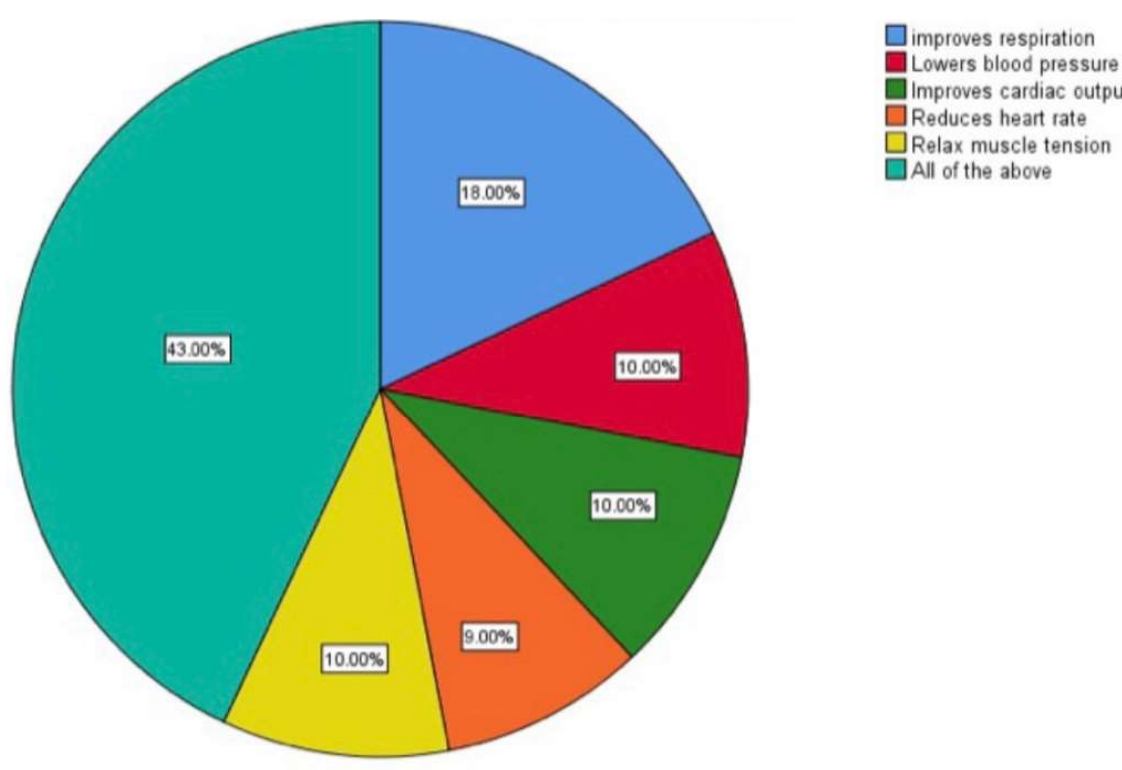

Figure 5: Pie chart representing participant's opinion on effects of music therapy. Majority 43\% (bluish green) agrees that, undergoing music therapy improves respiration, lowers blood pressure, improves cardiac output, reduces heart rate and relaxes muscle tension

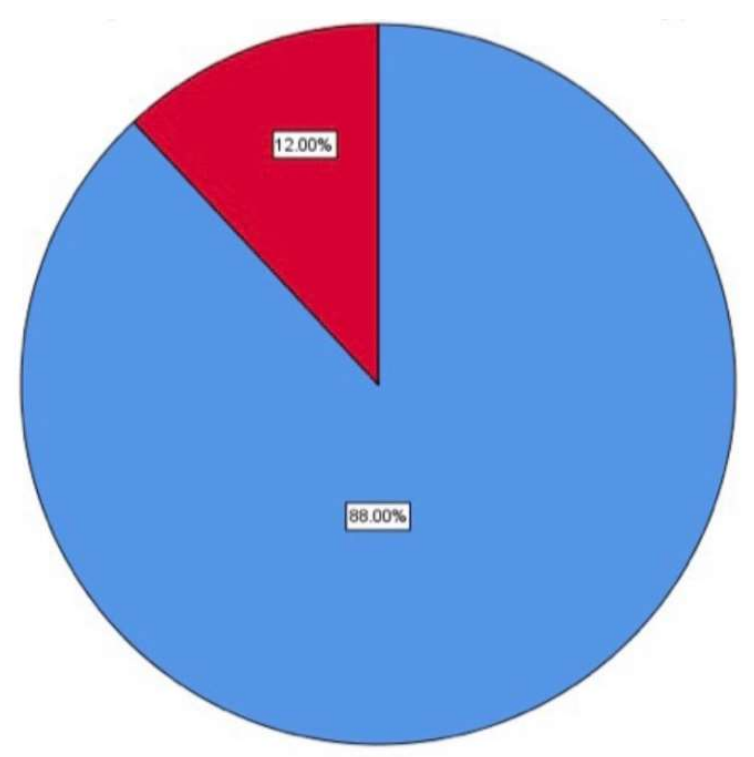

Bus

Figure 6: Pie chart representing participant's opinion about music therapy in treating patients medical problems. Majority $88 \%$ (blue) agrees and minority $12 \%$ (red) disagrees that music therapy reduces patients medical problems 


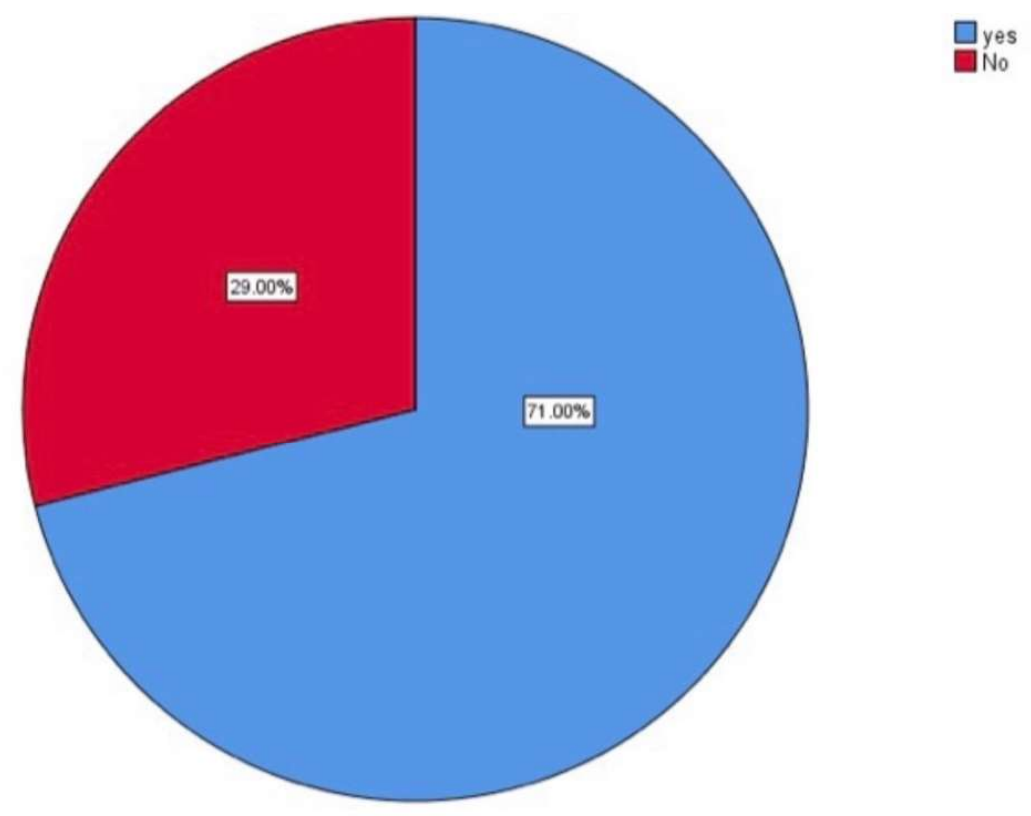

Figure 7: Pie chart representing participant's opinion about establishment of music therapy in India. Majority $71 \%$ (blue) says that music therapy is more established in India and minority $29 \%$ (red) says that music therapy is not well established in India

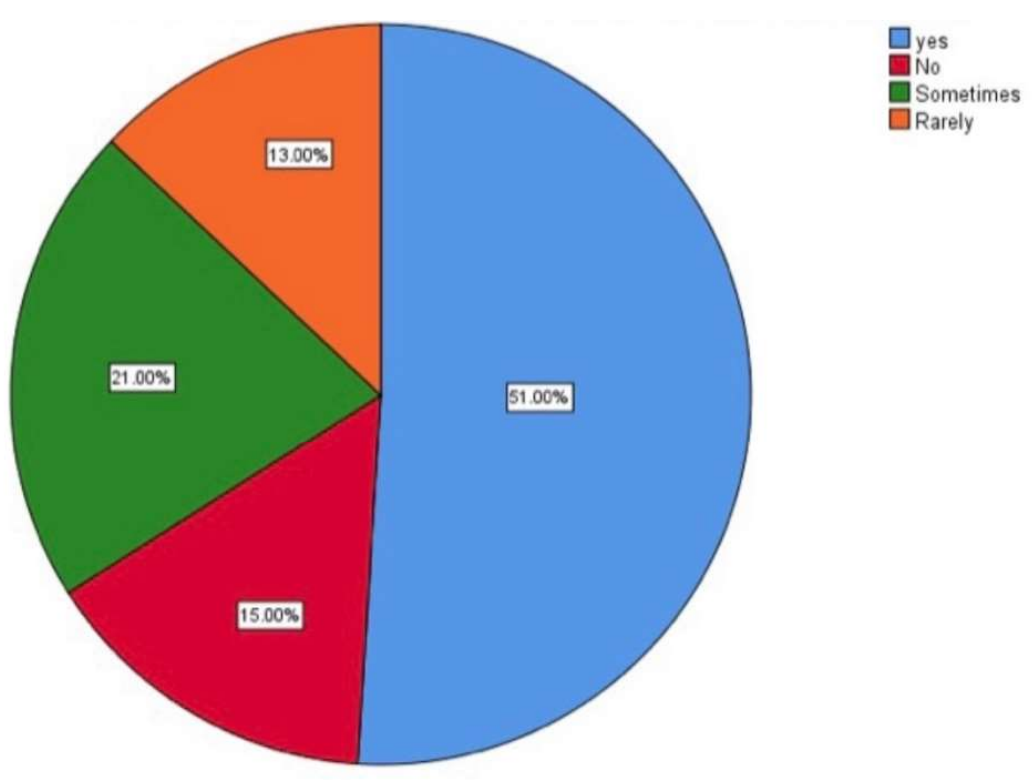

Figure 8: Pie chart representing participant's who listen to music when they have medical problems. Majority 51\% (blue) says 'yes', 15\% says (red) 'No', $21 \%$ (green) says 'sometimes', minority $13 \%$ (orange) says 'rarely' 


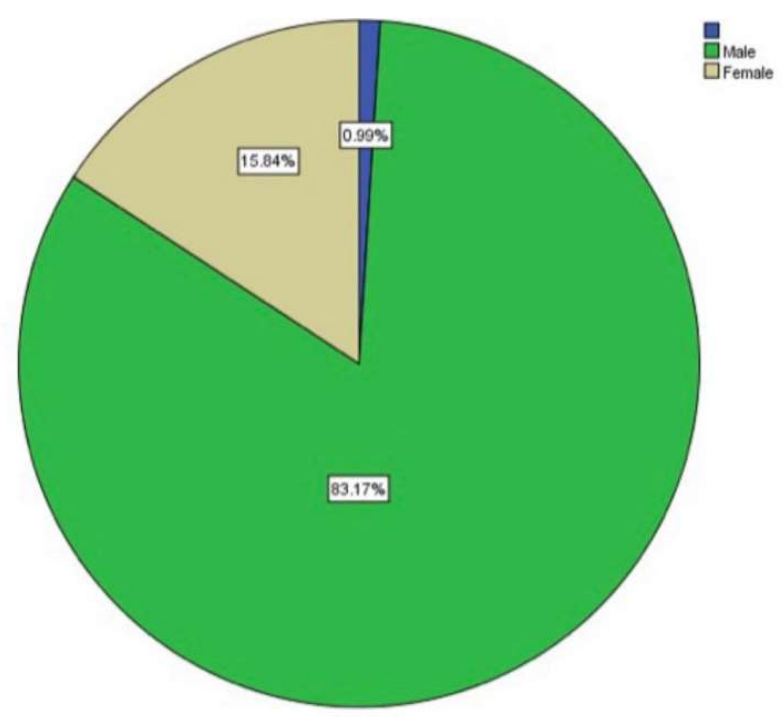

Figure 9: Pie chart representing participant's opinion on who will listen to more music. Majority $84 \%$ (green) says male listens to music and minority $17 \%$ (yellow) says female listens to more music

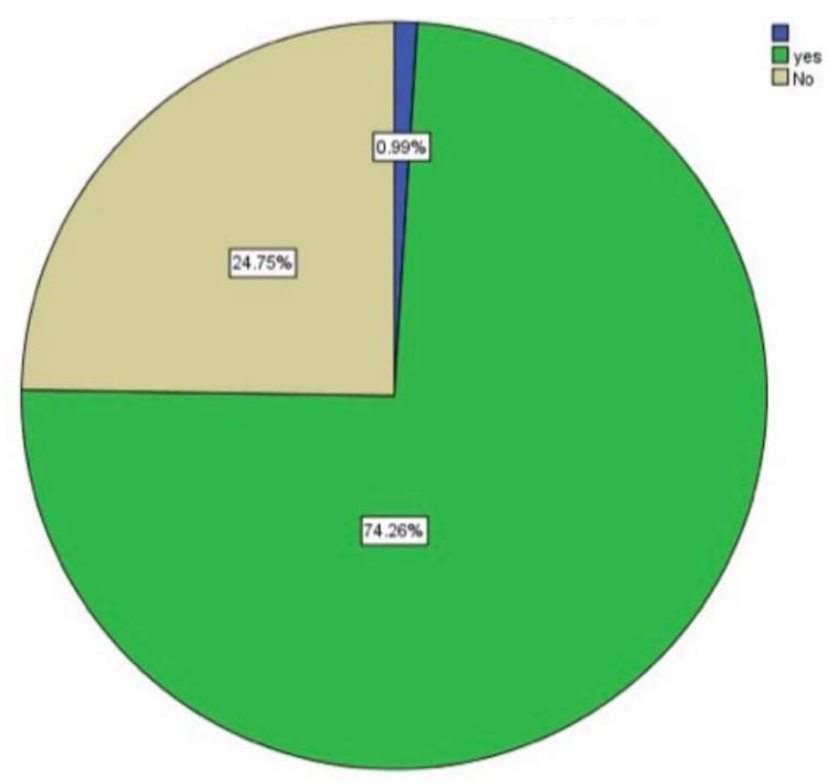

Figure 10: Pie chart representing participant's opinion whether music therapy is safe. Majority $75 \%$ (green) says that undergoing music therapy is safe and minority $25 \%$ (yellow) says that undergoing music therapy is not safe 


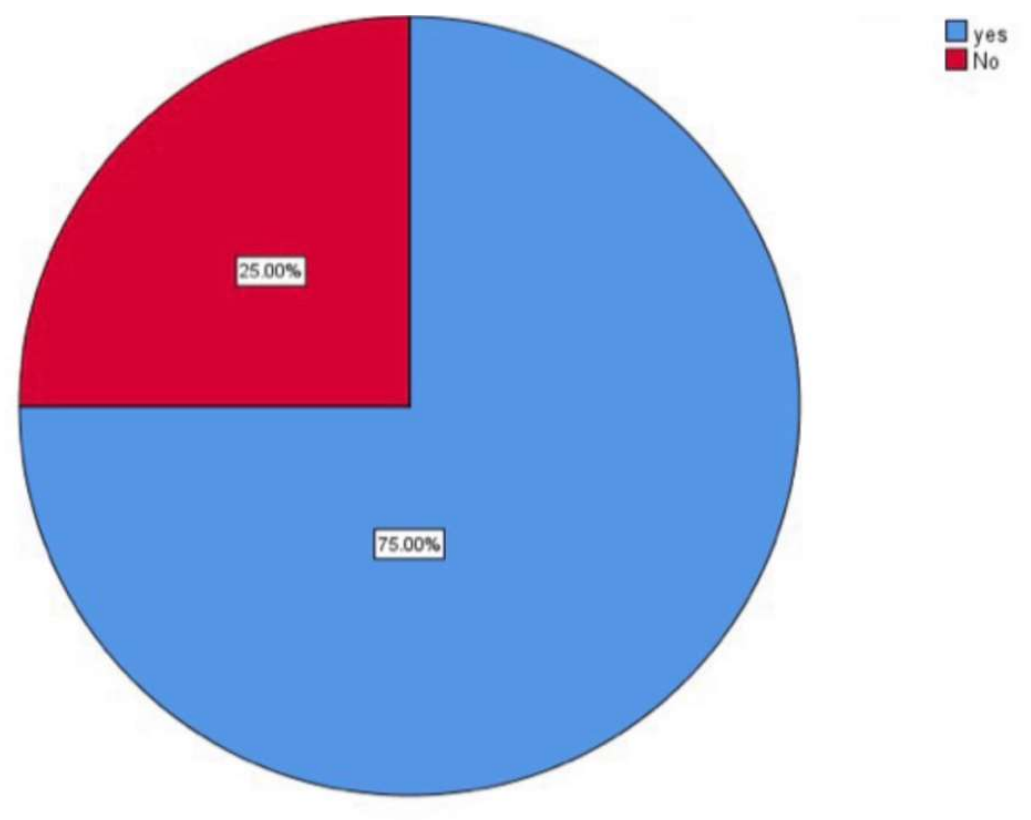

Figure 11: Pie chart representing participant's opinion whether they refer the patients to undergo music therapy. Majority $75 \%$ (blue) says that participants refer patients to undergo music therapy and minority $25 \%$ (red) says that they would not refer patients to undergo music therapy

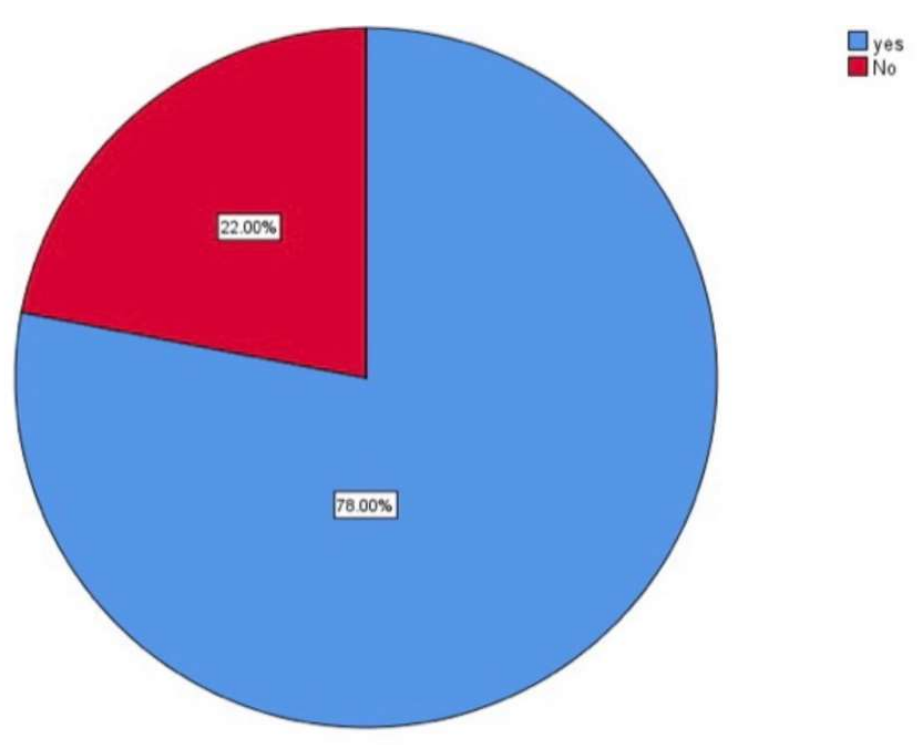

Figure 12: Pie chart representing participant's opinion about improving anxiety by undergoing music therapy. Majority $78 \%$ (blue) says that music therapy improves anxiety and minority $22 \%$ (red) says that music therapy does not improves anxiety 


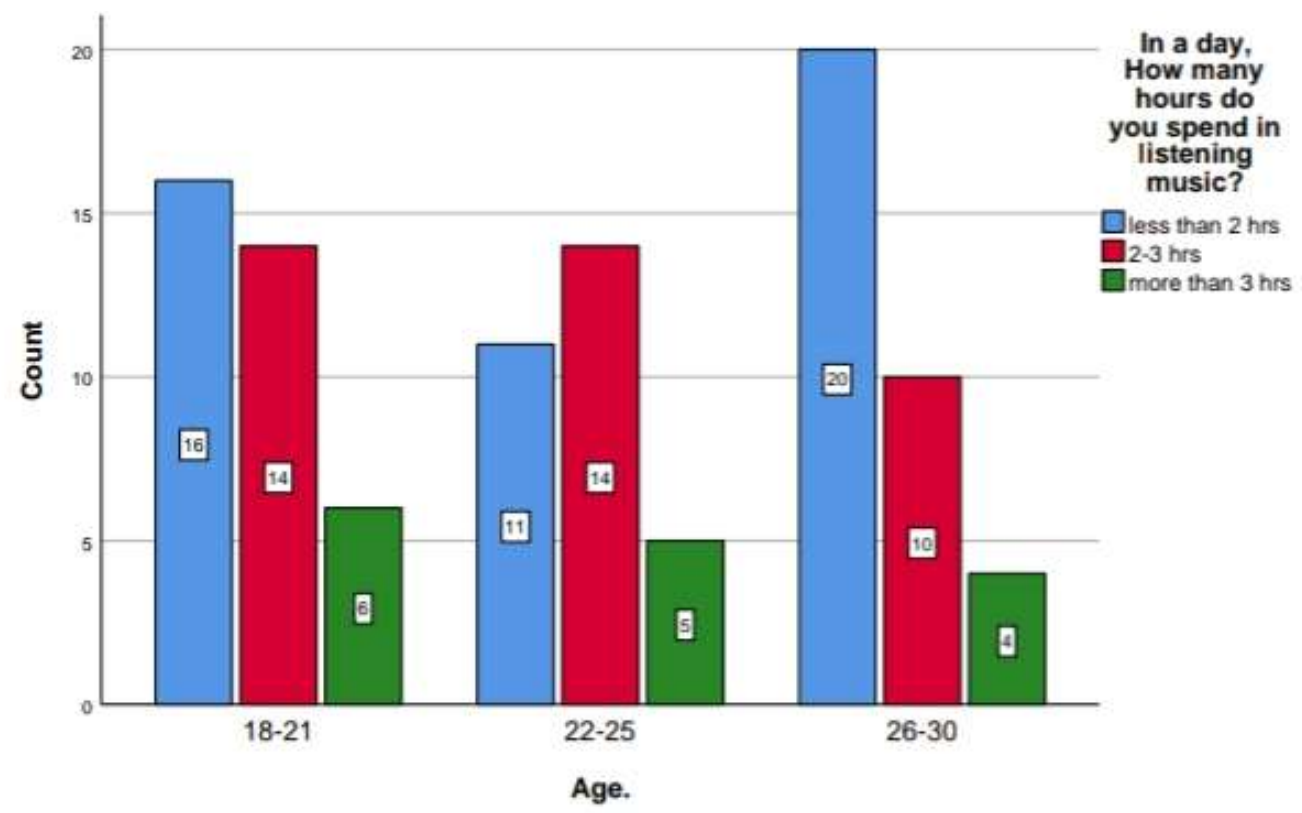

Figure 13: Bar graph representing association between age and time spent in listening to music. $X$-axis represents age and $\mathrm{Y}$-axis represents the no of participants in the time spent in listening to music. Pearson's Chi square value - 3.363, p value - 0.499 ( $p>0.005)$ hence not significant

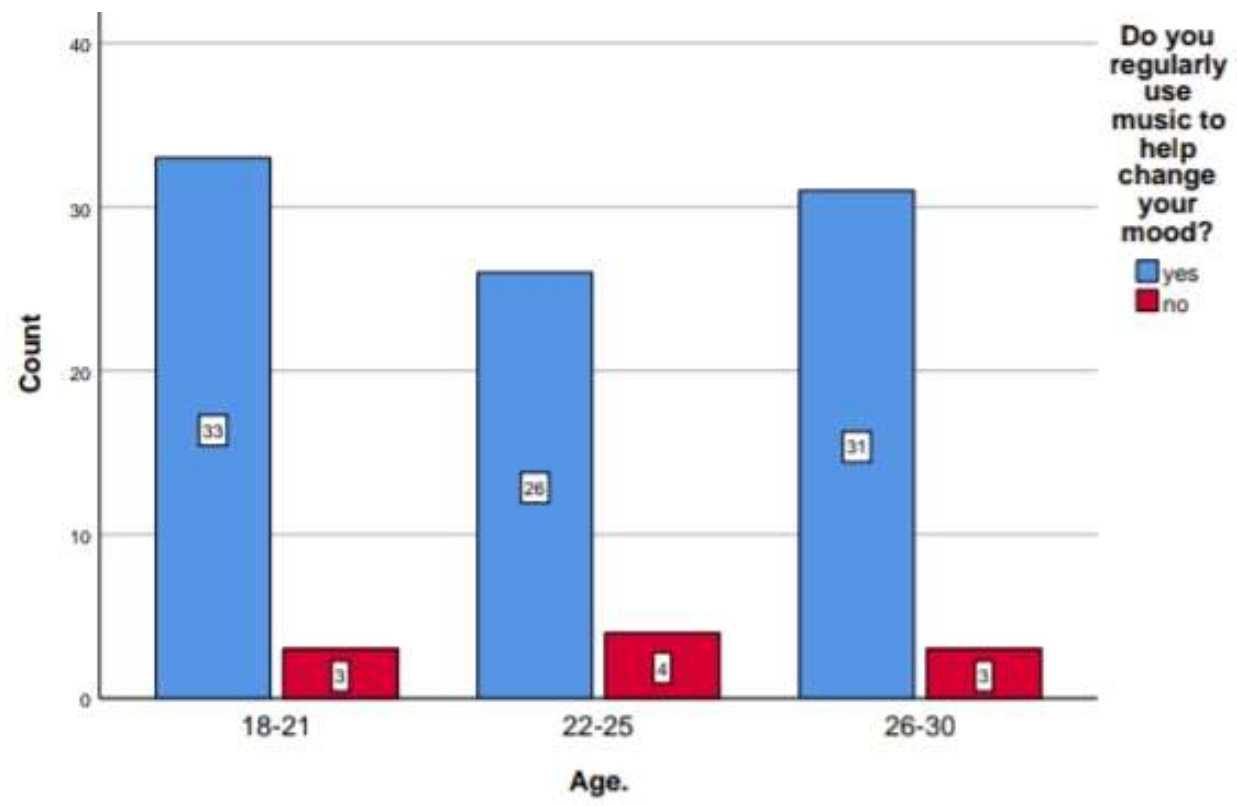

Figure 14: Bar graph representing association between age and role of music in mood change. $X$-axis represents age and $\mathrm{Y}$-axis represents the population opinion on the role of music in mood change. Pearson's Chi square value - 0.534, $p$ value $-0.766(p>0.05)$ Though a majority of the participants use music to change their mood, it is not statistically significant. 


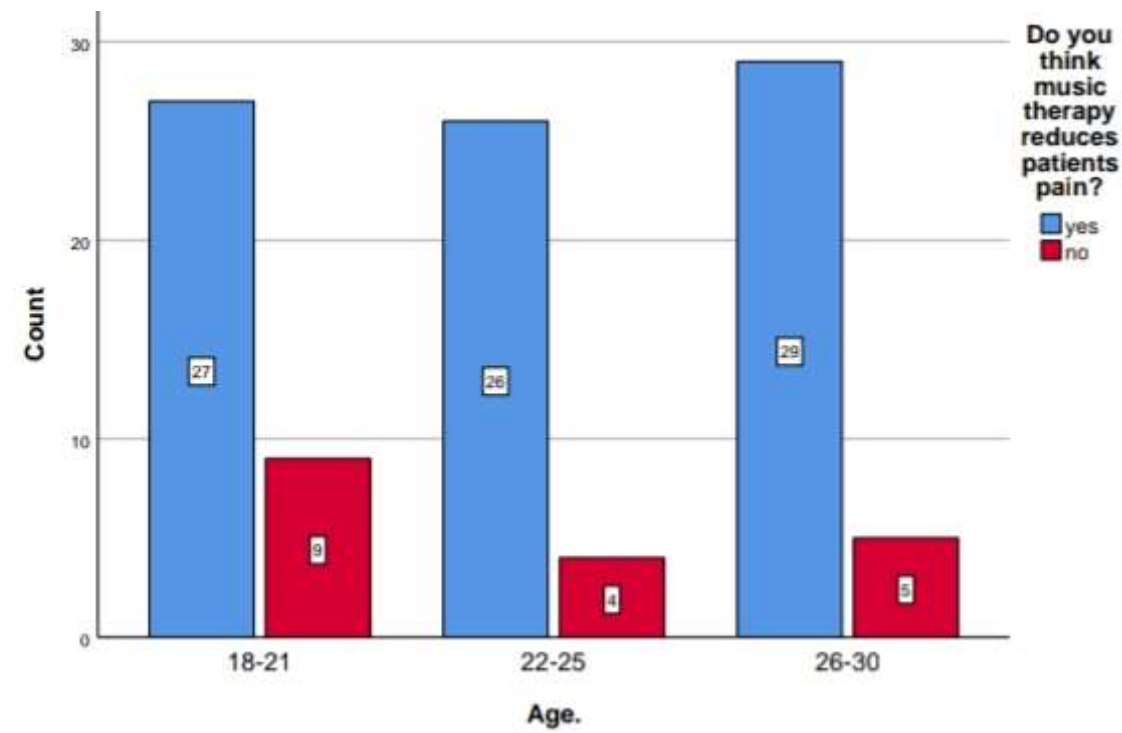

Figure 15: Bar graph representing association between age and role of music in reduction of pain. $\mathrm{X}$-axis represents age and $\mathrm{Y}$-axis represents population opinion on the role of music in reduction of pain. Pearson's Chi square value - 1.888, $p$ value $-0.389(p>0.05)$. Though a majority of the participants feel reduces patient's pain, it is not statistically significant.

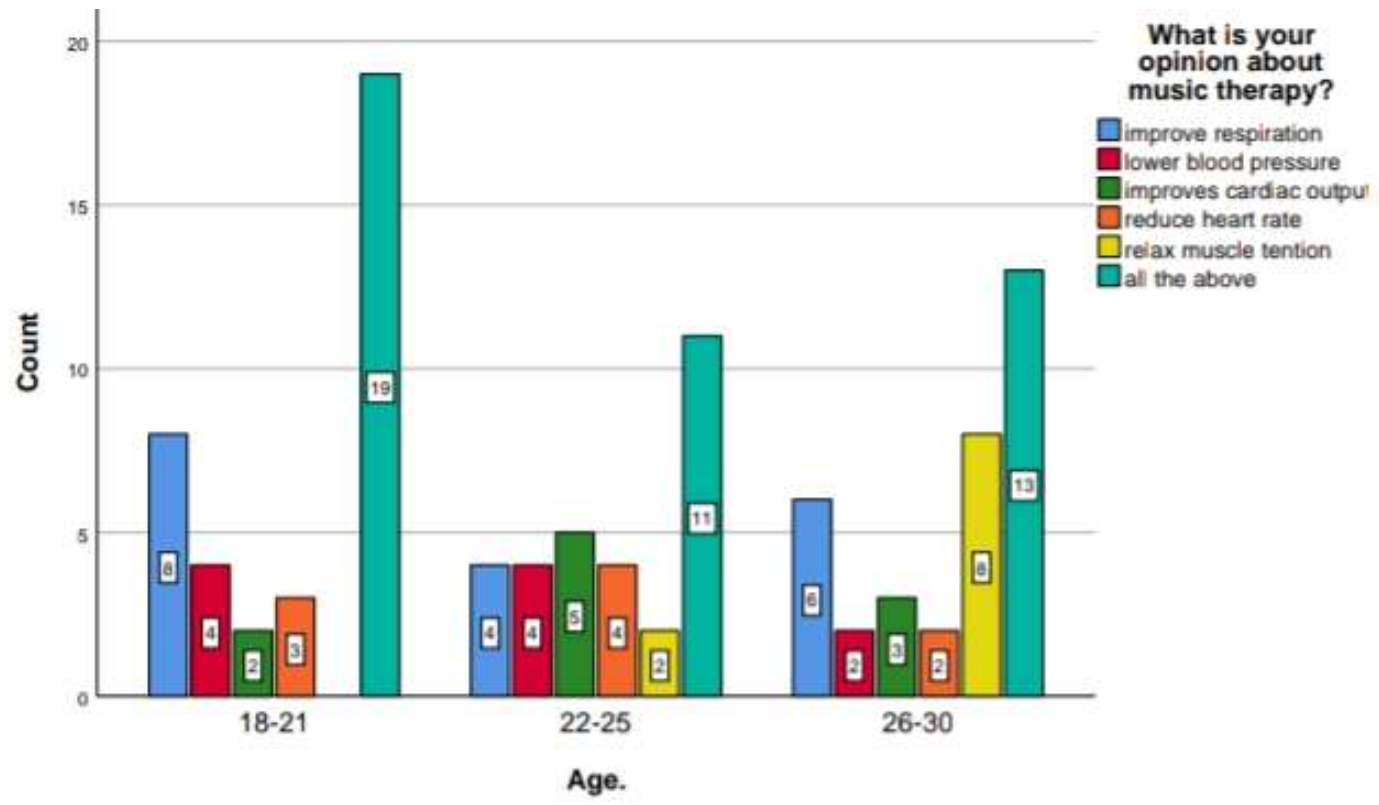

Figure 16: Bar graph representing association between age and population opinion about music therapy. $\mathrm{X}$-axis represents age and $\mathrm{Y}$-axis represents population opinion about music therapy. Pearson's Chi square value - 16.195, $p$ value - $0.094(p>0.05)$ hence not significant 


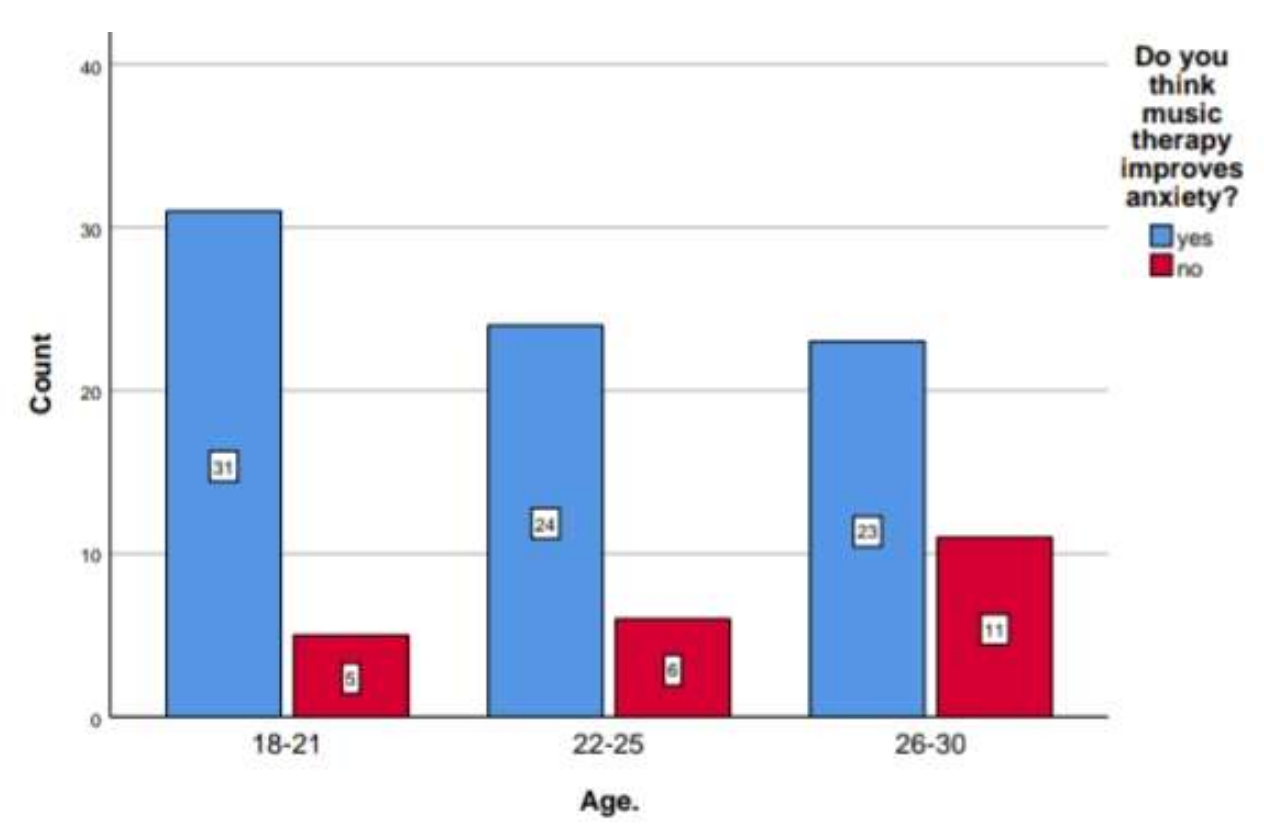

Figure 17: Bar graph representing association between age and role of music in anxiety level. $\mathrm{X}$-axis represents age and $\mathrm{Y}$-axis represents the population opinion on the role of music in anxiety level. Pearson's Chi square value - 3.574, $p$ value $\mathbf{- 0 . 1 6 7}(\mathrm{p}>\mathbf{0 . 0 5})$ Though a majority of the participants think music to reduce anxiety, it is not statistically significant.

\section{CONCLUSION}

Music therapy can be used for facilitating movement and overall physical rehabilitation and motivating patients to cope up with the treatment. It can provide emotional support for clients and their families, and provide an outlet for expression of feelings. Music therapy has more positive results in treating and curing patients who have medical problems which includes both physical and mental health issues. Music therapy also has an impact in sleep patterns. It also offers an important role in the management of meal related anxiety for patients. In clinical observation the therapeutic use of music often seems adequate and beneficial, but the empirical knowledge in our field is rare and limited, but growing. This study provides support for the future funding of inpatient music therapy programs and contributes to the evidence base for the use of music therapy with this population.

\section{REFERENCES}

[1] Grocke D, Bloch S, Castle D, Thompson G, Newton R, Stewart S, et al. Group music therapy for severe mental illness: a randomized embedded-experimental mixed methods study. Acta Psychiatr Scand. 2014 Aug; 130(2): 144-53.

[2] Hayashi N, Tanabe Y, Nakagawa S, Noguchi M, Iwata C, Koubuchi Y, et al. Effects of group musical therapy on inpatients with chronic psychoses: 
a controlled study. Psychiatry Clin Neurosci. 2002 Apr; 56(2): 187-93.

[3] Mössler K, Chen XJ, Heldal TO. Music therapy for people with schizophrenia and schizophrenia-like disorders. Cochrane Database Syst Rev [Internet]. 2011; Available from: https://www.cochranelibrary.com/cds r/doi/10.1002/14651858.CD004025.p ub3/abstract

[4] Rolvsjord R. Resource-oriented music therapy in mental health care. Barcelona Publishers Gilsum, NH; 2010.

[5] Paul S, Ramsey D. Music therapy in physical medicine and rehabilitation. Aust Occup Ther J. 2000 Sep; 47(3): 111-8.

[6] Fathima F. Preetha. Evaluation of Thyroid Function Test in Obese Patients. Asian J Pharm Clin Res. 2016; 9(3): 353-5.

[7] Samuel AR, Devi MG. Geographical distribution and occurrence of Endemic Goitre. Research Journal of Pharmacy and Technology. 2015; 8(8): 973-8.

[8] Harsha L, Priya J, Shah KK, Reshmi B. Systemic approach to management of neonatal jaundice and prevention of kernicterus. Research Journal of
Pharmacy and Technology. 2015; 8(8): 1087-92.

[9] Baheerati MM, Devi RG. Obesity in relation to Infertility. Research Journal of Pharmacy and Technology. 2018; 11(7): 3183-5.

[10] Iyer PK, Devi RG, Priya AJ. A Survey Study on Causes, Treatment and Prevention of Onychocryptosis. Indian Journal of Public Health Research \& Development. 2019; 10(8): 807-11.

[11] Dave PH, Others. Pathogenesis and Novel Drug for Treatment of Asthma-A Review. Research Journal of Pharmacy and technology. 2016; 9(9): 1519-23.

[12] Almerud S, Petersson K. Music therapy-a complementary treatment for mechanically ventilated intensive care patients. Intensive Crit Care Nurs. 2003 Feb 1; 19(1): 21-30.

[13] Bonny HL. Music and healing. Music Therapy [Internet]. 1986; Available from: https://academic.oup.com/musicther apy/article-abstract/6/1/3/2757016

[14] Dalton JH, Elias MJ, Wandersman A. Community psychology: Linking individuals and communities (2e 
éd.). Belmont, $\quad \mathrm{CA}$ :

Wadsworth/Thomson. 2007;

[15] Fitzsimons S, Fuller R.

Empowerment and its implications for clinical practice in mental health:

A review. J Ment Health. 2002 Jan

1; 11(5): 481-99.

[16] Rj I, Devi G. Role of environmental factors on sleep patterns of different age groups: A survey-based study. Asian J Pharm Clin Res. 2016; $9(6): 124-6$.

[17] Shruthi M, Preetha S. Effect of Simple Tongue Exercises in Habitual Snorers. Research Journal of Pharmacy and Technology. 2018; 11(8): 3614-6.

[18] Long S, Wallis D, Leung N, Meyer C. "All eyes are on you": anorexia nervosa patient perspectives of inpatient mealtimes. J Health Psychol. 2012 Apr 1; 17(3): 419-28.

[19] Hage TW, Rø Ø, Moen A. “Time's up"-staff's management of mealtimes on inpatient eating disorder units. Journal of eating [Internet]. 2015; Available from: https://jeatdisord.biomedcentral.com /articles/10.1186/s40337-015-00524
[20] McFerran K. Adolescents, Music and Music Therapy: Methods and Techniques for Clinicians, Educators and Students. Jessica Kingsley Publishers; 2010. 304 p.

[21] Hilliard RE. The effect of music therapy sessions on compassion fatigue and team building of professional hospice caregivers. The Arts in Psychotherapy. 2006 Jan 1; 33(5): 395-401.

[22] Robarts JZ, Sloboda A. Perspectives on Music Therapy with People Suffering from Anorexia Nervosa. Journal of British Music Therapy. 1994 Jun 1; 8(1): 7-14.

[23] Priya AJ, Devi G, Others. Physical Fitness among the Dental Physician, Dental Undergraduates and Postgraduates Students. Indian Journal of Public Health Research \& Development. 2019; 10(10): 223-6.

[24] Swathy S, Sethu VG. Acupuncture and lower back pain. Research Journal of Pharmacy and Technology. 2015; 8(8): 991-3. 